\title{
Distribution and divergent process of volatile phenols in bottom waters in Jiaozhou Bay
}

\author{
Dongfang Yang ${ }^{1,2,3, a}$, Sixi Zhu ${ }^{1,2}$, Yunjie $\mathrm{Wu}^{1,2}$, Xiuqin Yang ${ }^{1,2}$ and Fengyou \\ Wang $^{1,2, b, c}$
}

${ }^{1}$ Research Center for Karst Wetland Ecology, Guizhou Minzu University, Guizhou Guiyang, Guizhou Guiyang, China;

${ }^{2}$ College of Chemistry and Environmental Science, Guizhou Minzu University, Shanghai, 550025, China;

${ }^{3}$ North China Sea Environmental Monitoring Center, SOA, Qingdao 266033, China.

adfyang_dfyang@126.com; ${ }^{\mathrm{b} C}$ Corresponding author; 'wangfy2001@yahoo.com.cn.

Keywords: Volatile phenols; Water quality; Distribution; Bottom waters; Divergent process; Jiaozhou Bay

\begin{abstract}
Volatile phenols are a class of protoplasmic toxicants which have caused inevitable environmental problems in many sea areas. This paper analyzed the content, pollution level and distribution of volatile phenol in bottom waters Jiaozhou Bay in May, September and October 1983. Results showed volatile phenol contents ranged from $0.25 \sim 1.95 \mu \mathrm{g} \mathrm{L}^{-1}$ in bottom waters in the whole year, and were lower than Class I for volatile phenols $\left(5.00 \mu \mathrm{g} \mathrm{L}^{-1}\right)$ in National Standard of China for Seawater Quality (GB3097-1997). Jiaozhou Bay was very slightly contaminated by volatile phenols in 1983 under the impacts of vertical water's effect. Due to the flow rate was very fast in the bay mouth, in where were low value regions in different seasons in the bay mouth (0.25-1.50 $\left.\mathrm{g} \mathrm{L} \mathrm{L}^{-1}\right)$, indicated that there was a divergent process of volatile phenols in bottom waters in Jiaozhou Bay by means of water movement.
\end{abstract}

\section{Introduction}

Volatile phenols are a class of protoplasmic toxicants which have been widely used in industries of dyestuff, medicine, chemical, pesticide etc. A large amount of volatile phenol-containing waste water was generated and discharged to the environmental with the rapid increasing of these industries. In nowadays, volatile phenols pollution has been inevitable environmental problems in many sea areas [1-2].

Jiaozhou Bay is a semi-closed bay located in Shandong Province, eastern China. Due to the rapid increasing of industries after Chinese economic reform, this bay has been polluted by various pollutants including volatile phenols [1-2]. Based on the investigation data on volatile phenol in surface waters in different seasons in 1983, the aim of this paper was to analysis the content, pollution level and distribution of volatile phenols in bottom waters Jiaozhou Bay, and to provide basis for the research on the existence and transfer process of volatile phenols in bottom waters.

\section{Materials and method}

Jiaozhou Bay $\left(35^{\circ} 55^{\prime}-36^{\circ} 18^{\prime} \mathrm{N}, 120^{\circ} 04^{\prime}-120^{\circ} 23^{\prime} \mathrm{E}\right)$ is located in the south of Shandong Peninsula, eastern China. The area, bay mouth width and average water depth and maximum water depth are $390 \mathrm{~km}^{2}, 2.5 \mathrm{~km}$ and $7.0 \mathrm{~m}$, respectively (Fig. 1). This bay is surrounding by cities of Qingdao, Jiaozhou and Jiaonan in the east, north and south, respectively. The bay mouth is located in the south of the bay, and is connected with the Yellow Sea. There are more than ten inflow rivers such as Loushan River, Licun River and Haibo River, all of which are seasonal rivers [3-4].

The investigation on volatile phenols in five sampling sites (H34, H35, H36, H37 and H82) in Jiaozhou Bay waters was conducted by North China Sea Environmental Monitoring Center in May, 
September and October 1983 (Fig. 1). The investigation and measurement of volatile phenols were followed by National Specification for Marine Monitoring [5].

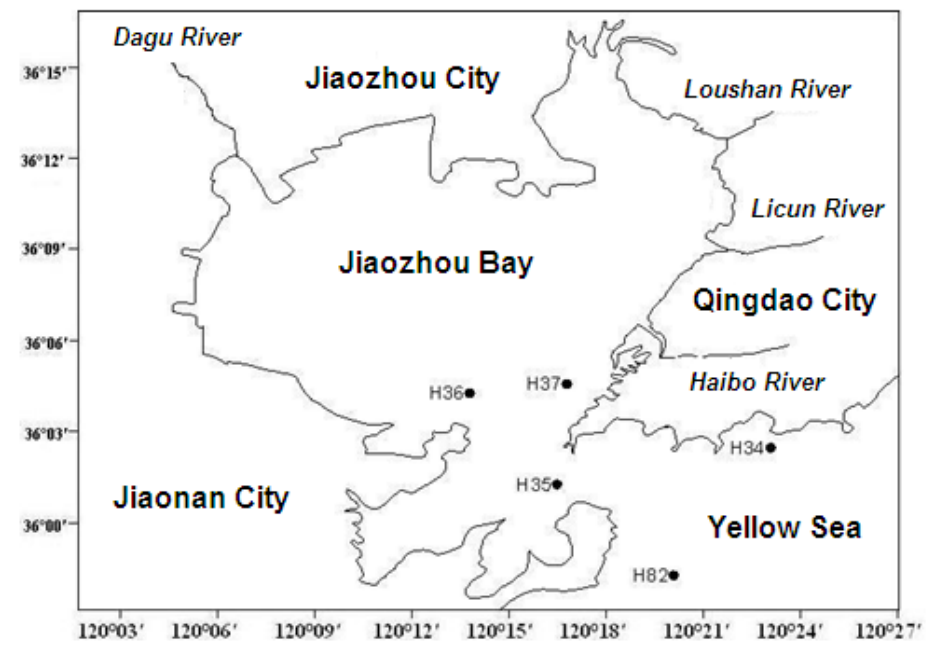

Fig.1 Geographic location and sampling sites of Jiaozhou Bay

\section{Contents and pollution levels of volatile phenols in bottom waters.}

Volatile phenols contents in Jiaozhou Bay bottom waters in May, September and October 1983 were ranged from $0.25-1.85 \mu \mathrm{g} \mathrm{L}^{-1}, 0.40-1.25 \mu \mathrm{g} \mathrm{L}^{-1}$ and $1.10-1.95 \mu \mathrm{g} \mathrm{L} \mathrm{L}^{-1}$, respectively, and were ranged from $0.25-1.95 \mu \mathrm{g} \mathrm{L}^{-1}$ in the whole year. In according to the guide line of Class I for volatile phenols $\left(5.00 \mu \mathrm{g} \mathrm{L}^{-1}\right)$ in National Standard of China for Seawater Quality (GB3097-1997). The major sources of volatile phenols in this bay were stream flow, overland flow, and marine current and marine terminals. In a source to sink perspective, volatile phenols were originally discharged to the surface waters in the bay, and were transferred to the sea bottom through the water body finally. Hence, the vertical water's effect was working during this transfer process [6], leading to the bottom waters in this bay was very slightly contaminated by volatile phenol in 1983.

\section{Distributions of volatile phenols in bottom waters.}

In May, there was a low value region for volatile phenols contents in the bay mouth (Fig. 2). A serious of semi-concentric circles were forming around the low value center, and were showing a decreasing trend from the external areas $\left(1.85 \mu \mathrm{g} \mathrm{L}^{-1}\right)$ to the the center $\left(0.25 \mu \mathrm{g} \mathrm{L}^{-1}\right)$. The distributions of volatile phenols contents in the bay mouth in September was similar to which in May (Fig. 3), and were also showing a decreasing trend from the external areas $\left(1.25 \mu \mathrm{g} \mathrm{L} \mathrm{L}^{-1}\right)$ to the center $\left(0.40 \mu \mathrm{g} \mathrm{L}^{-1}\right)$. In October, there was also a low value region for volatile phenols contents in the bay mouth (Fig. 4), and the serious of semi-concentric circles were forming around the low value center, and were showing a decreasing trend from the external areas $\left(1.95 \mu \mathrm{g} \mathrm{L}^{-1}\right)$ to the the center $\left(1.50 \mu \mathrm{g} \mathrm{L}^{-1}\right)$. Meanwhile, there was a relative high value of volatile phenols in Site H34 in the coastal waters outside the bay (Fig. 4). The distributions of volatile phenols in this region were forming a serious of parallel lines which were decreasing from the high value center to the south $\left(1.10 \mu \mathrm{g} \mathrm{L}^{-1}\right)$. Hence, it could be seen that there were low value regions in different seasons in the bay mouth. 


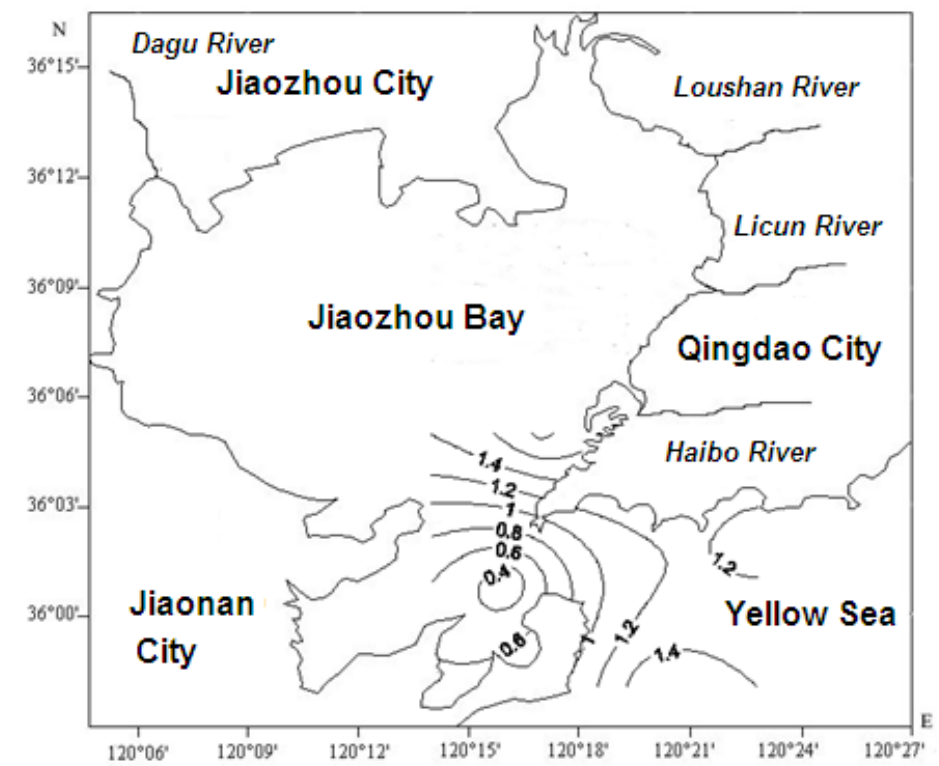

Fig. 2 Distributions of volatile phenols in bottom waters in Jiaozhou Bay in May 1983

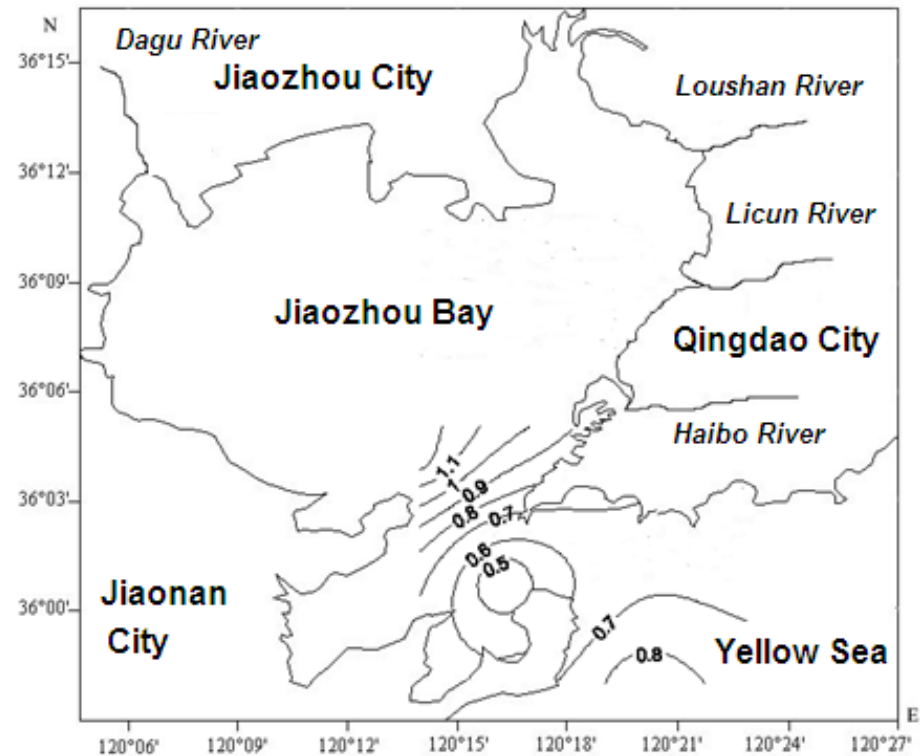

Fig. 3 Distributions of volatile phenols in bottom waters in Jiaozhou Bay in September 1983

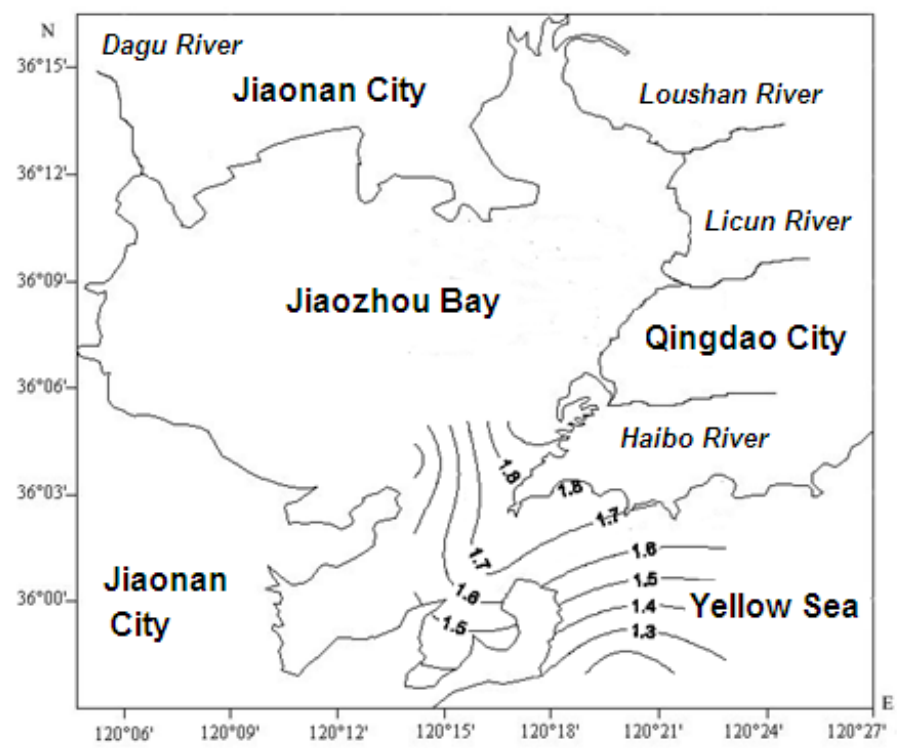

Fig. 4 Distributions of volatile phenols in bottom waters in Jiaozhou Bay in October 1983 


\section{Divergent process of volatile phenols in bottom waters.}

The east-west width and north-south length of Jiaozhou Bay are $27.8 \mathrm{~km}$ and $33.3 \mathrm{~km}$, respectively. Actually, there are two narrow bay mouths namely interior bay mouth $(2.5 \mathrm{~km})$ and exterior bay mouth $(3.1 \mathrm{~km})$, which were forming the bay mouth area of Jiaozhou Bay. There is a deep $(40 \mathrm{~m})$ water channel in the bay mouth area, in where the tidal current is very strong. For instance, the amplitude of tidal current of $\mathrm{M}_{2}$ is as high as $1 \mathrm{~m} \mathrm{~s}^{-1}$, and the instantaneous velocity of the flow in this water channel during the spring tide is $2.01 \mathrm{~m} \mathrm{~s}^{-1}$ [7]. The low value regions of volatile phenols contents in bottom waters were all occurring in Site H35 in the bay mouth area. The low value in May, September and October were $0.25 \mu \mathrm{g} \mathrm{L}^{-1}, 0.40 \mu \mathrm{g} \mathrm{L}^{-1}$ and $1.50 \mu \mathrm{g} \mathrm{L}^{-1}$, respectively. It could be seen that due to the high flow rate was high in the bay mouth, there were aggregation processes of volatile phenols by means of the movement of the water body.

\section{Low value region of volatile phenols in bottom waters.}

The ranges of water exchange time in marine bay could be defined by both conservative substance and non-conservative substance [8]. In the bay mouth area, by means of convection transport, dilute-diffusion, and the water exchange between the bay and open waters, the contents of the substances were decreasing continuously, and were showing the water exchange capacities of the bay. It could be found that were low value regions of volatile phenols in bottom waters different seasons in the bay mouth, and a serious of semi-concentric circles were forming around the low value center, and were showing a decreasing trend from the external areas to the center (Fig. 2-4). Similarly, there were also low value regions of PHC in bottom waters in the same region in September 1983, as well as low value regions of $\mathrm{Hg}$ in bottom waters in the same region in May 1983 and October 1985 [9]. That was the high flow rate in the bay mouth area could result in the decreasing of the contents of various substance, so as the low value regions. The distributions of volatile phenols in bottom waters in the bay mouth area in Jiaozhou Bay indicated the vertical water's effect.

\section{Conclusions}

Volatile phenols contents in Jiaozhou Bay bottom waters in May, September and October 1983 were ranged from $0.25-1.85 \mu \mathrm{g} \mathrm{L}^{-1}, 0.40-1.25 \mu \mathrm{g} \mathrm{L}^{-1}$ and $1.10-1.95 \mu \mathrm{g} \mathrm{L}{ }^{-1}$, respectively, and were ranged from $0.25-1.95 \mu \mathrm{g} \mathrm{L}^{-1}$ in the whole year. In according to the guide line of Class I for volatile phenols $\left(5.00 \mu \mathrm{g} \mathrm{L}^{-1}\right)$ in National Standard of China for Seawater Quality (GB3097-1997). The low value regions of volatile phenols contents in bottom waters were all occurring in Site H35 in the bay mouth area, and a serious of semi-concentric circles were forming around the low value center, and were showing a decreasing trend from the external areas to the center, indicated that there were aggregation processes of volatile phenols by means of the movement of the water body.

\section{Acknowledgement}

This research was sponsored by Doctoral Degree Construction Library of Guizhou Nationalities University, Education Ministry's New Century Excellent Talents Supporting Plan (NCET-12-0659), Education Ministry's New Century Excellent Talents Supporting Plan (NCET-12-0659), Project of Outstanding Technological Educators of Governor of Guizhou ([2012]71), Project of Low Carbon Technology Plan of Guiyang (2012205]), Project of Science and Technology Foundation of Guiyang (LKM[2012]05), Special Research Projects of High Level Talents of Guizhou Province (TZJF-2011-44), and Research Projects of Guizhou Nationalities University ([2014]02), Research Projects of Guizhou Province Ministry of Education (KY [2014] 266), Research Projects of Guizhou Province Ministry of Science and Technology (LH [2014] 7376). 


\section{Reference}

[1] Yang DF, He HZ, Zhu SX, et al.:Materials, Environmental and Biological Engineering, (2015), pp. 343-346.

[2] Yang DF, He XH, Gao J, et al.: Materials, Environmental and Biological Engineering, (2015), pp.1103-1106.

[3] Yang DF, Chen Y, Gao ZH, et al.: Chinese Journal of Oceanology and Limnology, Vol. 23 (2005), pp. 72-90.

[4] Yang DF, Wang F, Gao ZH, et al.: Marine Science, Vol. 28(2004), p. 71-74. (in Chinese)

[5] State Ocean Administration. The specification for marine monitoring: Beijing, Ocean Precess, (1991). (in Chinese)

[6] Yang DF, Wang FY, He HZ, et al.: Proceedings of the 2015 international symposium on computers and informatics, 2015, p. 2655-2660.

[7] Lu XG, Zhao C, Xia CS. Acta Oceanologica Sinica, Vol. 32 (2010), p. 20-30. (in Chinese)

[8] Yang DF, Miao ZQ, Xu HZ, et al.: Marine Environmental Science, Vol. 332 (2013), p. 373-380. (in Chinese)

[9] Yang DF, Zhu SX, Wang FY, et al.: 2014 IEEE workshop on advanced research and technology industry applications. Part D, 2014, p.1012-1014. 